ISSN (Online): 2621-0851

Volume 1, Nomor 2, November 2018

\title{
ANALISIS IMPLIKATUR PERCAKAPAN DALAM PEMBELAJARAN PADA MAHASISWA IAIN SURAKARTA
}

\author{
Siti Isnaniah \\ Tadris Bahasa Indonesia FITK IAIN Surakarta \\ Posel:sisnaniah7@gmail.com
}

\begin{abstract}
Language plays an important role in communication domain. The role of a language would be an impact towards the receiver as the listener. In communication process, language is used as a mean of information exchange among humans. In addition, the language function speech out in different products. It means that there is an inconsistency between the speech and the meaning. This study actually would be discussing on speech implication. Speech implication concept is used to explain the differences appear between what was utterance and what was implicated. The method used in the research was qualitative descriptive. The place where the research conducted was IAIN Surakarta. The data source of the research were the informants; the situation, and the documents. The techniques of data collection were indepth interviewing, observation, and documents analysis. The sampling technique was purposive sampling. The data was analyzed by using the interactive analysis model. The results of the research were implication which is found on the speech, happen because the disorder of relevance maxim, quantity maxim, quality maxim, and maxim of way. Each implicate has its own certain objective and meaning by its speaker.
\end{abstract}

Keywords: speech; implication; maxim.

\begin{abstract}
Abstrak
Bahasa memegang peran penting dalam berkomunukasi. Peranan ini akan berdampak pada penerimaan lawan tutur terhadap penuturnya. Dalam proses interaksi pembelajaran, bahasa digunakan sebagai media transfer ilmu antara guru dengan siswanya. Kadang fungsi bahasa yang dituturkan dalam bentuk yang berbeda. Artinya, apa yang dituturkan dengan apa yang dimaksudkan tidak selalu sama. Kajian inilah yang akan dibahas dalam implikatur percakapan. Konsep implikatur percakapan digunakan untuk menerangkan perbedaan yang sering terjadi antara apa yang diucapkan dengan apa yang diimplikasikan. Metode yang digunakan dalam penelitian ini adalah metode deskriptif kualitatif. Tempat penelitian di IAIN Surakarta. Sumber data penelitian adalah informan, peristiwa, dan dokumen. Pengumpulan data diperoleh dengan menerapkan metode wawancara mendalam, observasi, dan analisis dokumen. Pengambilan sampel dilakukan dengan teknik purposive sampling atau sampel bertujuan. Analisis data dilakukan dengan menggunakan metode analisis interaktif. Hasil penelitian ini adalah ditemukannnya implikatur dalam percakapan dalam pembelajaran, hal itu terjadi karena adanya pelanggaran maksim relevansi, maksim kuantitas, maksim kualitas, dan maksim cara. Masing-masing implikatur memiliki maksud dan tujuan tertentu oleh setiap penuturnya.
\end{abstract}

Kata kunci: prcakapan; implikatur; maksim.

\section{PENDAHULUAN}

Bahasa merupakan alat terpenting dalam komunikasi. Dengan bahasa, perasaan, ide, dan pikiran bisa terungkapkan dengan baik (Hestiyana 2018: 50). Ada beberapa alat yang dapat berperan demi kelangsungan komunikasi. Di antaranya adalah isyarat, aneka simbol, kode, maupun bunyi. Namun demikian, semua itu akan bermakna jika diterjemahkan ke dalam bahasa. Dengan bahasa manusia mampu mengkomunikasikan segala hal. Oleh sebab itu, bahasa disebut sebagai alat komunikasi terpenting bagi manusia (Rohmadi, 2004).

Sebagai alat komunikasi bahasa memiliki beberapa fungsi. Fungsi bahasa yang paling penting adalah informasional, sebagai alat penyampai informasi. Suatu komunikasi akan berlangsung dengan baik jika antara penutur dan lawan tutur terdapat kesepahaman. Ada banyak faktor yang menentukan kelancaran berkomunikasi. Kata-kata, kalimat-kalimat saja tidak cukup 
melancarkan komunikasi. Faktor-faktor nonlinguistik seperti pendidikan, tingkat ekonomi, situasi, siapa pembicara, siapa pendengar juga menjadi faktor penentu pemakaian bahasa dalam komunikasi, sehingga komunikasi berlangsung dengan baik.

Senada dengan pernyataan di atas, Lubis (1991:5) menyatakan bahwa kita berbicara dengan alat bicara kita, tetapi kita berkomunikasi dengan tubuh kita yang ditentukan oleh situasi, dan kondisi di tempat kita berada. Lebih lanjut Hasan Lubis menjelaskan bahwa dengan mengetahui sekalian faktor-faktor nonlinguistik dengan mudah pembicaraan itu dapat kita tafsirkan dengan pengalaman kita pada situasi dan kondisi yang sama yang telah kita alami pada masa lalu. Faktorfaktor linguistik tersebut sering kita sebut konteks.

Situasi yang memungkinkan terjadinya kegiatan komunikasi yang optimal adalah dalam pembelajaran (Gino, 1999: 30). Bertolak dari pendapat Gino tersebut dapat disimpulkan bahwa pembelajaran yang optimal tidak akan terlepas dari komunikasi (antara pengajar dengan mahasiswa). Pembelajaran yang optimal menuntut adanya sebuah komunikasi yang baik.

Ada kalanya dalam komunikasi antara apa yang dituturkan dengan apa dimaksudkan tidak sama. Hal itulah yang sering disebut dengan implikatur percakapan. Perbedaan tuturan dan maksud tersebut baik sengaja maupun tidak sengaja diciptakan dengan maksud tertentu. Tuturan seorang penutur akan dipahami dengan baik oleh lawan tutur dengan adanya kerjasama yang baik antara keduanya karena percakapan tersebut melibatkan pembicara dan pendengar atau pembaca dan penulis dengan melibatkan konteks percakapan (Akbar, 2018: 27). Oleh sebab itu, kesepahaman bersama merupakan hal terpenting dalam berinteraksi (Purwo, 1990: 20). Bahasa yang digunakan dalam percakapan saat berinteraksi akan mudah berpengaruh pada interaksi tersebut.

Bahasa menunjukkan bangsa. Eksistensi suatu bangsa bisa dikenali dari budi dan bahasanya. Penggunaan bahasa oleh suatu komunitas juga akan berpengaruh terhadap pembentukan karakter suatu bangsa. Apakah suatu bangsa berkarakter kuat atau tidak salah satunya karena penggunaan bahasa. Oleh sebab itu, penggunaan bahasa dalam komunikasi harus sesuai dengan konteksnya. Holmes (1993) menyatakan bahwa bahasa itu memiliki status dalam kehidupan sesuai dengan kedudukan dan fungsinya di suatu negara atau komunitas. Terdapat status bahasa tinggi (High Language) dan status rendah (Low Language). Dalam acara-acara resmi negara tentunya harus menggunakan bahasa yang berstatus tinggi, yakni bahasa Indonesia sesuai dengan kaidah-kaidahnya. Sedangkan dalam komunikasi sehari-hari bisa menggunakan bahasa yang berstatus rendah, misalnya di Surakarta bisa menggunakan bahasa Jawa, di Bandung bisa memakai bahasa Sunda, dll.

Berdasarkan uraian di atas, penulis akan membahas tentang tindak tutur dalam pembelajaran pada mahasiswa IAIN Surakarta. Sebagai seorang mahasiswa tentunya harus bisa menggunakan bahasa sesuai dengannya. Hal tersebut karena dengan banyanyaknya interaksi secara verbal, dimungkinkan lebih banyak terjadi implikatur. Selain itu, implikatur yang sering digunakan pengajar akan mudah berpengaruh pada bahasa mahasiswa sehingga tuturan mahasiswa juga akan lebih banyak mengandung implikatur percakapan. 


\section{METODE PENELITIAN}

Penelitian ini dilaksanakan di IAIN Surakarta. Bentuk penelitian ini adalah deskriptif kualitatif. Dalam penelitian ini peneliti menganalisis hasil rekaman tindak tutur yang mengandung unsur implikatur percakapan dalam komunikasi dan memahami makna yang tersirat di dalamnya.

Adapun dalam penelitian ini peneliti memperoleh data dari tiga sumber, yaitu: peristiwa, informan, dan dokumen. Sampel penelitian ini adalah tuturan pengajar dan mahasiswa dalam komunikasi di IAIN Surakarta. Pengambilan sampel dilakukan dengan teknik purposive sample atau sampel bertujuan. Sampel yang diambil merupakan sampel yang dianggap memuat implikatur percakapan di IAIN Surakarta.

Teknik pengumpulan data dalam penelitian ini dengan menggunakan observasi, wawancara mendalam, dan analisis dokumen. Analisis data dilakukan dengan menggunakan metode aktif interaktif. Data mentah yang diperoleh di lapangan dipilih yang berkenaan dengan masalah implikatur percakapan. Data yang telah direduksi kemudian disajikan dalam bentuk laporan secara sistematik sehingga memudahkan penarikan simpulan. Adapun simpulan tersebut perlu diverifikasi selama penelitian berlangsung. Peneliti juga perlu meninjau ulang reduksi data maupun penyajian data sehingga simpulan final yang diambil tidak menyimpang dari data yang dianalisis.

\section{HASIL DAN PEMBAHASAN}

\section{Bentuk Implikatur Tindak Tutur Mahasiswa IAIN Surakarta}

Dari penelitian yang telah peneliti lakukan, terdapat beberapa bentuk implikatur percakapan antara dosen dengan mahasiswa IAIN Surakarta. Bentuk-bentuk tersebut di antaranya sebagai berikut:

1. Dosen : Kalian nanti akan membuat dongeng sebagai tugas akhir perkuliahan. Mahasiswa : Laab!

2. Dosen : Ini kepunyaan siapa?

Febi : (mengacungkan jari)

3. Dosen : Ini punya Ferdian ya? Kok nggak dikasih nama?

4. Dosen : Ferdian, Febi!

5. Dosen : Febi, Febi!

6. Dosen : ...Ferdian, masak tulisan Aulia tidak bisa dibaca sih? Tidak bisa dibaca atau tidak bisa mengerjakan?

7. Dosen : Waktunya sudah mau habis ya.

8. Kalau nilainya 100 tapi hasil nyontek?

9. Dosen : Mungkin kalian bisa membohongi ibu, tapi ada yang tahu lho ya. Di sini sama di sini lho ya.

10. Dosen : Febi, Febi! Di depan kelas aja ya?

11. Dosen : Kok Ferdian cuma mengarang dua paragraf sih?

12. Dosen : Apa yang dimaksud dengan diksi Anis?

Anis : Kata-kata yang digunakan dalam mengarang Bu.

Dosen : Lho kok kata-kata? Diksi lho ya. Kata-kata itu kan sifatnya masih umum.

13. Dosen : Siapa tahu apa yang dimaksud dengan diksi?

Dwi : (mengacungkan jari) 


\section{SeBaSa: Jurnal Pendidikan Bahasa dan Sastra Indonesia}

14. Dosen : Ya, bagus ya.

15. Dosen : Rifki di mana ya?

16. Dosen : Iring-iringan jenazah itu pergi ke pemakaman. Benar atau salah kalimat tersebut?

Mahasiswa : Salah (menjawab dengan serentak)

Dosen : Udah disuruh menjawab? Kenapa menjawab?

17. Dosen: Siapa yang ketahuan tidak tertib dalam mengerjakan soal nanti ketemu sama saya di kantor. Siapa yang mau ketemu sama saya?

18. Dosen: Febi kok tidur ya?

19. Aulia, white board-nya di mana?

20. Dosen: Yang putra mau belajar nggak? Kalau nggak dosen ngajar yang putri aja.

21. Dosen: Misal dosen ingin menulis Rabu. Bagaimana cara nulisnya Dwi?

Dwi: R-A-B-U (mengeja)

Dosen: Ya, benar R-A-B-U (sambil tersenyum)

Dwi: R-nya besar.

\section{Maksud dan Sebab Terjadinya Implikatur Tindak Tutur Mahasiswa IAIN Surakarta}

Ujaran "Laah" (1) yang diucapkan mahasiswa secara serentak dimaksudkan sebagai tanda ketidaksetujuan jika tugas akhir perkuliahan nanti berupa pembuatan makalah. Kata tersebut sering digunakan masyarakat Jawa, jika ingin mengungkapkan ketidaksetujuannya atau kekecewaannya terhadap sesuatu.

Acungan jari pada data nomor (2) dan (13) untuk menunjukkan jati diri (keakuan), punya saya, saya bisa, saya ingin berpendapat, atau yang lainnya. Selain itu dosen mengakui memang setiap akan menjawab pertanyaan terlebih dahulu mahasiswa dianjurkan untuk mengacungkan jari. Biasanya para mahasiswa pun aktif mengacungkan jari ketika dosen melontarkan pertanyaan, meskipun akhirnya jawaban mereka benar ataupun salah.

Pertanyaan dosen "Ini punya Ferdian ya?" (3) sebenarnya hanya sebagai penegasan karena beliau mengaku sudah hafal beberapa bentuk tulisan mahasiswanya. Kemudian dilanjutkan dengan kalimat "Kok nggak dikasih nama?", kalimat tersebut menyiratkan perintah agar lembar pertanyaan yang telah dibuatnya diberi nama. Dosen memang kadang memerintah mahasiswa tanpa kalimat perintah langsung. Biasanya dengan diberi pertanyaan semacam itu, mahasiswa sudah memahaminya.

Panggilan dosen terhadap beberapa nama mahasiswanya seperti tampak pada data nomor (4), (5) dan (10) bermaksud mengingatkan para mahasiswa yang ramai saat mengerjakan soal di dalam kelas. Memanggil nama dengan nada yang lebih tinggi daripada nada normal, apalagi dengan kata yang diulang-ulang, para mahasiswa sudah bisa menanggapi bahwa dirinya ditegur. Dosen memang tidak memberi peringatan secara lengkap karena dengan menyebut nama saja mahasiswa sudah memahami. Hal tersebut dilakukan dosen agar mahasiswa bisa memahami sendiri apa dan bagaimana dia harus melakukan sesuatu karena dianggap sudah dewasa.

Pertanyaan dosen pada nomor (6) sebagai penyelidik tindakan tidak langsung dosen karena adakalanya kejujuran tidak bisa diungkap secara langsung. Dosen ingin melakukan suatu tindakan dengan mengatakan sesuatu pada pertanyaan ini.

Ujaran dosen "Waktunya sudah mau habis ya." (7) merupakan perintah agar soal segera diselesaikan. Seperti kalimat sebelumnya, dengan kalimat ini dosen menunjukkan suatu tindakan (perintah) dengan menggunakan pernyataan. Selanjutnya dosen bertanya "Kalau nilainya seratus 
tapi hasil nyontek?" (8) merupakan ungkapan bahwa nyontek bukan perbuatan yang baik meskipun akan menghasilkan nilai yang baik. Selain itu, juga merupakan larangan kepada mahasiswa agar tidak nyontek dalam mengerjakan soal. Dosen memberi pertanyaan tersebut karena beliau ingin menyatakan larangan.

Pernyataan dosen pada nomor (9) juga dimaksudkan untuk memberi peringatan pengajaran akhlak bahwa ada malaikat yang mencatat seluruh perbuatan kita, perbuatan baik atau buruk, dengan menunjukkan tangan kanan sebagai tempat pencatat perbuatan baik dan pencatat perbuatan buruk berposisi di tangan kiri. Dengan simbol-simbol tersebut biasanya mahassiswa sudah memahaminya.

Kalimat "Ya, bagus ya." sebagai pernyataan bahwa jawaban yang diungkapkan Dwi benar. Dosen sering memberikan penghargaan kepada mahasiswa yang menjawab pertanyaan dengan benar. Dengan pemberian penghargaan tersebut mahasiswa akan lebih termotivasi untuk aktif menjawab pertanyaan.

Pertanyaan dosen "Rifki di mana ya?" (15) Sebenarnya bukan sekedar untuk bertanya, tetapi kalimat tersebut mempunyai makna yang lebih dalam, yaitu sebuah perintah dosen kepada Anisa agar segera masuk ke dalam kelas. Kalimat tanya tersebut muncul sebagi penghalus perintah.

Kalimat tanya "Udah disuruh menjawab?" (16) merupakan kalimat peringatan dosen agar mahasiswa bisa tertib dalam menjawab pertanyaan yang diberikan dosen, karena pada perjanjian awal sudah disepakati bahwa ketentuan untuk menjawab adalah mengacungkan tangan dan ditunjuk oleh dosen. Kalimat tersebut mungkin bisa diimplikasikan sebagai berikut. "Tadi kesepakatan kita bisa menjawab setelah ibu tunjuk, jadi jangan menjawab sebelum ibu menunjuk salah satu mahasiswa untuk menjawab."

Ujaran dosen "Nanti ketemu sama saya" pada (17) mempunyai makna yang lebih dalam dari sekedar bertemu. Jika mahasiswa tidak tertib dalam mengerjakan soal maka akan ada sanksi yang diberikan oleh dosen akibat perbuatannya. Namun kata sanksi tersebut diperhalus dengan kata ketemu. Meskipun demikian mahasiswa pun bisa mengerti apa yang dimaksudkan dosen.

Pertanyaan dosen "Febi kok tidur ya?" (18) sebenarnya bermaksud menyindir Fauzi yang saat jam pelajaran tertidur. Jadi kalimat tanya tersebut mungkin dapat diimplikasikan "Febi, ini jam pelajaran, kamu tidak boleh tidur."

Pertanyaan dosen yang ditujukan dosen terhadap Aulia pada (19) juga untuk memperhalus perintah agar Aulia memperhatikan pelajaran ke papan tulis saat jam pelajaran berlangsung. Memang, diakui dosen bahwa pada saat jam pelajaran seringkali Aulia menoleh ke belakang, menghadap ke temannya yang duduk di belakangnya.

Dua kalimat tanya yang diungkapkan pada ujaran (20) tidak sekedar untuk bertanya. Kalimat tersebut mempunyai makna perintah kepada mahasiswa agar tidak gaduh dan ramai saat jam perkuliahan berlangsung. Dengan pertanyaan tersebut para mahasiswa putra langsung terdiam.

Pertanyaan dosen pada ujaran (21) tidak bermaksud menanyakan bagaimana menulis "Rabu", namun dimaksudkan untuk menanyakan cara penulisan nama hari yang benar. Pada awalnya Dwi kurang memahami pertanyaan dosen, namun setelah dosen memberikan senyuman meskipun dengan kata benar Dwi paham bahwa jawaban yang dia lontarkan salah.

\section{Maksim-maksim Prinsip Kerja Sama Grice yang Dilanggar Pada Percakapan Mahasiswa IAIN Surakarta}

Pada ujaran nomor (1) melanggar maksim kuantitas karena pernyataan tidak setuju dengan kata tersebut kurang informatif. Selain itu juga melanggar maksim cara karena ungkapan tersebut 


\section{SeBaSa: Jurnal Pendidikan Bahasa dan Sastra Indonesia}

bersifat kabur, arti kurang jelas jika lawan bicara tidak memahami konteksnya, namun karena dalam percakapan tersebut lawan bicara mengerti konteks pembicaraan maka berterima.

Pada nomor (2) dan (13) mahasiswa hanya menggunakan bahasa tubuh sebagai komunikasi. Hal tersebut bisa dipahami dosen, namun sebenarnya bahasa tubuh tersebut bisa berarti ganda, tidak memberi informasi berupa bahasa lisan. Maksim yang dilanggar sama dengan kalimat (1)

Kalimat (3) tidak relevan dengan apa yang dimaksudkan, sebab dosen menegaskan dengan pertanyaan, padahal dosen sudah mengetahui hal tersebut juga terjadi pada kalimat selanjutnya, dosen memerintah dengan sebuah pertanyaan. Dosen mengetahui bahwa pertanyaan itu tidak sebenarnya dilakukan, maka kedua kalimat tersebut juga melanggar maksim kualitas, namun karena adanya alasan tertentu dosen menggunakannya.

Peringatan dosen pada nomor (5) dan (10) melanggar maksim kuantitas, sebab dosen tidak memberikan informasi yang informatif, sehingga pernyataan kurang jelas. Bisa jadi panggilan tersebut merupakan panggilan yang sesungguhnya atau larangan untuk sesuatu yang lain, namun lawan bicara memahami bahwa maksud dosen adalah memberi peringatan karena mahasiswa gaduh saat perkuliahan berlangsung.

Kalimat nomor (6), (7), (8) melanggar maksim relevansi sebab dosen mengatakan sesuatau yang tidak sesuai dengan apa yang dimaksudkannya. Selain itu kalimat-kalimat dosen bisa menyebabkan makna yang kabur, jadi ujaran-ujaran tersebut juga melanggar maksim cara.

Dengan bahasa tubuh, menunjukkan tangan kanan dan kiri, sambil berkata "Di sini dan di sini" (9), yang menunjukkan adanya dua malaikat, menyebabkan makna kabur dan kurang jelas sehingga melanggar maksim cara.

Pertanyaan dosen pada nomor (11) dan (12) melanggar maksim relevansi, sebab maksud dari pertanyaan berbeda dengan apa yang ditanyakan. Selain itu juga melanggar maksim kuantitas, karena informasi yang diberikan kurang, sehingga menyebabkan ketidakjelasan yang mengakibatkan pelanggaran maksim cara.

Pernyataan "bagus" (14) juga melanggar maksim relevansi dan cara, sebab pernyataan bahwa jawaban Dwi benar diucapkan dengan pemberian reward "bagus". Kata tersebut juga menimbulkan makna ganda, apanya yang bagus? Namun lawan bicara bisa memahaminya.

Ujaran dosen pada nomor (15) melanggar maksim relevansi karena dengan pertanyaan tersebut dosen bermaksud menegur mahasiswa yang tidak dapat duduk dengan tenang pada saat perkuliahan. Jadi tidak ada hubungan antara ujaran dosen dengan maksudnya. Akan tetapi mahasiswa dapat memahami ujaran dosen.

Dosen ingin menegaskan agar para mahasiswa menepati ketentuan yang telah diungkapkan di awal bahwa para mahasiswa diizinkan menjawab pertanyaan setelah mengacungkan jari. Penegasan itu dimulai dengan sebuah pertanyaan seperti pada nomor (16). Dengan demikian, pertanyaan dosen tersebut melanggar maksim relevansi.

Pada ujaran data ke (17) "Nanti ketemu saya" melanggar maksim kuantitas sebab informasi yang diberikan dosen kurang lengkap. Tujuan dari ketemu saya untuk apa tidak diungkapkan dosen tetapi para mahasiswa bisa memahami ujaran tersebut dengan menghubungkan ujaran dosen tentang ketidaktertiban mahasiswa saat mengerjakan soal.

Pertanyaan dosen "Febi kok tidur ya?" melanggar maksim kuantitas karena sumbangan yang diberikan kurang informatif kalimat. Kalimat tersebut mungkin bisa diperjelas dengan kalimat "Febi kok tidur ya? Ini kan jam perkuliahan, jadi Febi tidak baik tidur di kelas."

Pertanyaan dosen pada data nomor (19) melanggar maksim hubungan karena pertanyaan itu bukan bermaksud bahwa dosen belum mengetahui letak white board tetapi untuk mengingatkan 
Aulia yang tidak memusatkan perhatian ke dosen yang mengajar namun ke teman yang berada di belakangnya.

Ujaran dosen pada data nomor (20) melanggar maksim hubungan karena pertanyaan tersebut menyiratkan teguran agar para mahasiswa memperhatikan penjelasan yang diberikan dosen, bukan untuk bertanya mau belajar atau tidak. Namun demikian, para mahasiswa mampu memahami ujaran dosen kemudian merespon teguran dosen tersebut.

Dialog antara dosen dan Dwi pada data nomor (21) Misal dosen ingin menulis Rabu. Bagaimana cara nulisnya Dwi? melanggar maksim hubungan. Ujaran dosen kepada Dwi bermaksud menyuruh Dwi untuk menentukan huruf yang seharusnya huruf kapital. Sedangkan ujaran dosen, Ya, benar $\mathrm{R}-A-B-U$ melanggar maksim kualitas. Kata benar yang diucapkan dosen disertai senyum memiliki arti jawabannya salah karena maksud dosen tidak dipahami Dwi.

\section{SIMPULAN}

1. Implikatur percakapan yang sering terjadi dalam pembelajaran di IAIN Surakarta dalam bentuk kalimat khususnya kalimat tanya.

2. Sebagian besar dari implikatur percakapan yang terjadi di IAIN Surakarta bermaksud memperhalus tuturan.

3. Terjadi pelanggaran keempat maksim prinsip kerja sama Grice pada ujaran yang mengandung implikatur yang dianalisis. Terdapat beberapa kalimat yang melanggar lebih dari satu maksim.

4. Implikatur percakapan mahasiswa IAIN Surakarta berpengaruh terhadap karakter bangsa. Sebagai seorang mahasiswa tentunya harus bisa menggunakan bahasa sesuai dengan konteks dan status bahasa.

5. Sebelum memulai mengajar dosen harus memahami sejauh mana tingkat pemahaman mahasiswanya agar bisa memastikan wacana seperti apa yang bisa digunakan untuk memahamkan ilmu kepada mahasiswanya. Selain itu dosen juga diharapkan bisa membuat suasana kelas yang variatif agar mahasiswa tidak mengalami kejenuhan dalam belajar. Caracara tersebut bisa ditemukan salah satunya dengan mengkaji ilmu pragmatik, sebab ilmu pragmatik mengkaji bahasa dalam kaitannya dengan makna yang berhubungan dengan konteks.

6. Implikatur percakapan bermanfaat bagi pembelajaran di antaranya untuk menegur mahasiswa dengan cara yang baik dan memperhalus tindak tutur. Akan tetapi penggunaan tersebut harus diimbangi dengan pemahaman dosen terhadap kemampuan mahasiswa memahami tuturan dosen.

\section{DAFTAR PUSTAKA}

Bambang Kaswanti Purwo. 1990. Pragmatik dan Pengajaran. Yogjakarta: Kanisius.

Brown, Gillian. 1996. Analisis Wacana. Diterjemahkan oleh I. Soetikno. Jakarta: Gramedia Pustaka Utama

Dewa Putu Wijana, I. Dasar-Dasar Pragmatik. Yogjakarta: Penerbit Andi. Gino H.J. 1999. Belajar dan Pembelajaran I. Surakarta: Depdikbud UNS.

Hestiyana. 2018. "Tindak Tutur Representatif dalam Komik Sepatu Dahlan Karya Tita Larasati (Adaptasi dari Novel Sepatu Dahlan Karya Khrisna Pabichara)". Jurnal Jalabaha Balai Bahasa Jawa Tengah, Vol. 14 (1), p. 50. 
SeBaSa: Jurnal Pendidikan Bahasa dan Sastra Indonesia

Muhammad Rohmadi. 2002. Pragmatik Teori dan Analisis. Yogyakarta: Lingkar Media.

Syahrizal Akbar. 2018. "Analisis Tindak Tutur pada Wawancara Putra Nababan dan Presiden Portugal (Kajian Pragmatik)". Jurnal Sebasa. Vol. 1 (1). P. 27.

Sutopo, H. B. 2002. Metodologi Penelitian Kualitatif: Dasar Teori dan Penerapannya dalam Penelitian. Surakarta: Sebelas Maret University Press. 